Available online on 15.12.2020 at http://jddtonline.info
Open Access to Pharmaceutical and Medical Research
unrestricted non-commercial use (CC By-NC), provided the original work is properly cited

Open 2 Access

Research Paper

\title{
Epidemioclinical profile and management of post thrombotic syndrome in Antananarivo
}

\author{
T Rajaobelison ${ }^{1}$, ZL Randimbinirina ${ }^{*}$, RNAL Rakotorahalahy ${ }^{1}$, AML Ravalisoa ${ }^{2}$, AJC Rakotoarisoa ${ }^{2}$ \\ (1) Department of Surgery, Faculty of Medicine Antananarivo, Antananarivo, 101, Madagascar \\ (2) Department of surgery, Faculty of Medicine Antananarivo, University of Antananarivo, 101, Madagascar
}

\begin{abstract}
Introduction: The post-thrombotic syndrome (PTS) is the most complication of deep vein thrombosis who deserves an early management. The aim of this study was to determine the epidemio-clinical profile and the management of PTS.

Methods: This was a retrospective and descriptive study for a period of 6 years from January 2013 to December 2018, performed at the Cardiovascular Surgery Unit in JRA Teaching Hospital Antananarivo, including all patients who presented post-thrombotic syndrome after an acute episode of deep venous thrombosis.

Results: 106 patients were recorded among 315 patients who presented an episode of DVT (33.65\%) and 14110 patients admitted in this period $(0.75 \%)$. The average age was 46.18 years old. There were 30 males $(28.30 \%)$ and 76 female (71.69\%). The most important risk factors of PTS were previous history of varicose veins (50\%), sedentary lifestyle (45.28\%), insufficiency of anticoagulant therapy (68.86\%) and proximal DVT (47.16\%). Delayed of diagnosis were greater than or equal to 2 years after an acute DVT in 86 patients (81.13\%). The most clinical signs were edema (56.60\%) and varicose veins (54.71\%). According the Villalta's score, PTS were mild in 48 patients (45.28\%), moderate in 47 patients (44.33\%) and severe in 11 patients (10.37\%). Management was lifestyles change (45.28\%), compression stockings $(100 \%)$, anticoagulant therapy (100\%) and surgical treatment $(65.09 \%)$.
\end{abstract}

Conclusion: The frequency of PTS was $33.65 \%$ in our study. PTS reduces quality of life of patients, but it can be avoided if the treatments of DVT are adapted.

Keywords: Deep vein thrombosis, Post-thrombotic syndrome, Epidemiology, Management

Article Info: Received 11 Oct 2020; $\quad$ Review Completed 17 Nov 2020; $\quad$ Accepted 28 Nov 2020; Available online 15 Dec 2020

Cite this article as:

Rajaobelison T, Randimbinirina ZL, Rakotorahalahy RNAL, Ravalisoa AML, Rakotoarisoa AIC, Epidemioclinical profile and management of post thrombotic syndrome in Antananarivo, Journal of Drug Delivery and Therapeutics. 2020; 10(6-s):1621 http://dx.doi.org/10.22270/jddt.v10i6-s.4420

*Address for Correspondence:

Dr Randimbinirina Zakarimanana Lucas, Department of Surgery, Faculty of Medicine Antananarivo, Antananarivo, 101, Madagascar

\section{INTRODUCTION}

Postthrombotic syndrome is defined as a presence of symptomatology and or chronic venous signs after deep vein thrombosis in the lower limbs. ${ }^{1}$ PTS is the most frequent complication of DVT, which develops in 20 to $50 \%$ of cases after proximal DVT and is severe in $5-10 \%$ of cases. $^{2}$ According the literature, the cumulative incidence of PTS for 2 years after an acute episode of DVT is $23-60 \%$, but the cumulative incidence of severe PTS for 5 years is $1-30 \%$. $^{3}$ PTS has been increasingly recognized as a serious public health problem. Because of venous ulcer, the patient's quality of life is seriously affected because of obstacles to daily routine activities and increased cost of treatment. According to Ma's study in 2014, the mean total cost of treating venous leg ulcers in contemporary vascular practice was $\$ 15,732.4$ One major issue in early PTS research concerned the risk factors and the management of PTS. PTS is little-known, underappreciated by practitioner in Madagascar and there is no consensus among their management. The aim of this study was to describe the epidemioclinical profile and management of PTS in our department.

\section{METHODS}

We conducted a retrospective and descriptive study for a period of 6 years from January 2013 to December 2018, performed at the Cardiovascular Surgery Unit in JRA Teaching Hospital Antananarivo, including all patients who presented postthrombotic syndrome after an acute episode DVT. 


\section{Inclusion criteria}

All patients who had a previous history of acute DVT and presenting symptoms or clinical signs of chronic venous insufficiency (greater than or equal to 3 month after an acute episode of DVT) were included in this study.

\section{Exclusion criteria}

Patients presented a symptomatology or clinical signs of chronic venous insufficiency but not having a previous history of DVT had been excluded.

Data were collected from patients folders stored at the Cardiovascular Surgery Unit in Joseph Ravoahangy Andrianavalona (JRA) Teaching Hospital Antananarivo.
Demographic data, risk factors of PTS, delay of diagnosis after initial DVT, symptoms and clinical signs, Villalta score, results of duplex ultrasound and management. Statistical analysis was performed by use of the SPSS $® 21$ statistics software program.

\section{RESULTS}

One hundred and six patients were recorded among 315 patients who presented a previous history of DVT $(37.73 \%)$ and 14110 patients admitted during this period $(0.75 \%)$. The average age was 46.18 years old (from 19 to 88 years old) and $8.49 \%$ of patients was older than 60 years. Patients were 30 males (28.30\%) and 76 females (71.69\%), giving a sex ratio of 0.39 (Table I).

Table I : Characteristics of study participants.

\begin{tabular}{|l|c|c|c|}
\hline \multicolumn{1}{|c|}{ Characteristics } & \multicolumn{2}{|c|}{$\begin{array}{c}\text { No. of Patients } \\
\text { (Total=106) }\end{array}$} & Percentage (\%) \\
\hline Gender & Male & 30 & 28.30 \\
\hline \multirow{4}{*}{ Age category (years) } & Female & 76 & 71.69 \\
\cline { 2 - 4 } & $0-30$ & 11 & 10.37 \\
\cline { 2 - 4 } & $31-40$ & 25 & 23.58 \\
\cline { 2 - 4 } & $41-50$ & 44 & 41.50 \\
\cline { 2 - 4 } & $51-60$ & 17 & 16.03 \\
\cline { 2 - 4 } & $61-70$ & 04 & 03.77 \\
\cline { 2 - 4 } & $\geq 71$ & 05 & 04.71 \\
\hline
\end{tabular}

The most important risk factors of PTS were previous history of varicose veins (50\%), sedentary lifestyle (45.28\%), insufficiency anticoagulation therapy $(68.86 \%)$ and proximal DVT (47.16\%) (Table II). Delayed diagnosis of PTS after an acute DVT were greater than or equal to 2 years in 86 patients $(81.13 \%)$ and less than 2 years in 20 patients
(18.86\%). Symptoms were pain (42.45\%), cramps (28.30\%), heaviness $(51.88 \%)$, pruritus $(18.86 \%)$ and paresthesia $(20.75 \%)$. The most clinical signs were edema (56.60\%) and varicose veins $(54.71 \%)$. According the Villalta's score, PTS were mild in 48 patients (45.28\%), moderate in 47 patients $(44.33 \%)$ and severe in 11 patients $(10.37 \%)$ (Table II).

Table II : Risk factors of PTS and diagnosis

\begin{tabular}{|c|c|c|c|}
\hline \multicolumn{2}{|c|}{ Risk factors and diagnosis } & \multirow{2}{*}{$\begin{array}{c}\begin{array}{c}\text { No. of Patients } \\
\text { (Total=106) }\end{array} \\
09\end{array}$} & \multirow{2}{*}{$\begin{array}{c}\begin{array}{c}\text { Percentage } \\
(\%)\end{array} \\
08.49\end{array}$} \\
\hline \multirow{7}{*}{ Risk factors } & Advanced age ( $\geq 60$ years) & & \\
\hline & Obesity (BMI $\left.\geq 30 \mathrm{~kg} / \mathrm{m}^{2}\right)$ & 25 & 23.58 \\
\hline & Previous history of reccurent DVT & 35 & 33.01 \\
\hline & Previous history of varicose veins & 53 & 50.00 \\
\hline & Sedentary lifestyle & 48 & 45.28 \\
\hline & Insufficiency anticoagulation therapy & 73 & 68.86 \\
\hline & Proximal DVT & 50 & 47.16 \\
\hline \multirow{2}{*}{$\begin{array}{l}\text { Delay of diagnosis after } \\
\text { initial DVT }\end{array}$} & $<2$ years & 20 & 18.86 \\
\hline & $\geq 2$ years & 86 & 81.13 \\
\hline \multirow{5}{*}{ Symptoms } & Pain & 45 & 42.45 \\
\hline & Cramps & 30 & 28.30 \\
\hline & Heaviness & 55 & 51.88 \\
\hline & Pruritus & 20 & 18.86 \\
\hline & Paresthesia & 22 & 20.75 \\
\hline \multirow{7}{*}{ Clinical signs } & Telangiectasia & 35 & 33.01 \\
\hline & Varicose veins & 58 & 54.71 \\
\hline & Edema & 60 & 56.60 \\
\hline & Hyperpigmentation & 22 & 20.75 \\
\hline & White scar tissue & 20 & 18.86 \\
\hline & Lipodermatosclerosis & 15 & 14.15 \\
\hline & Venous ulcer & 11 & 10.37 \\
\hline \multirow{3}{*}{ Villalta's PTS score } & Mild (5-9) & 48 & 45.28 \\
\hline & Moderate (10-14) & 47 & 44.33 \\
\hline & Severe $(\geq 15$ or presence of ulcer) & 11 & 10.37 \\
\hline
\end{tabular}




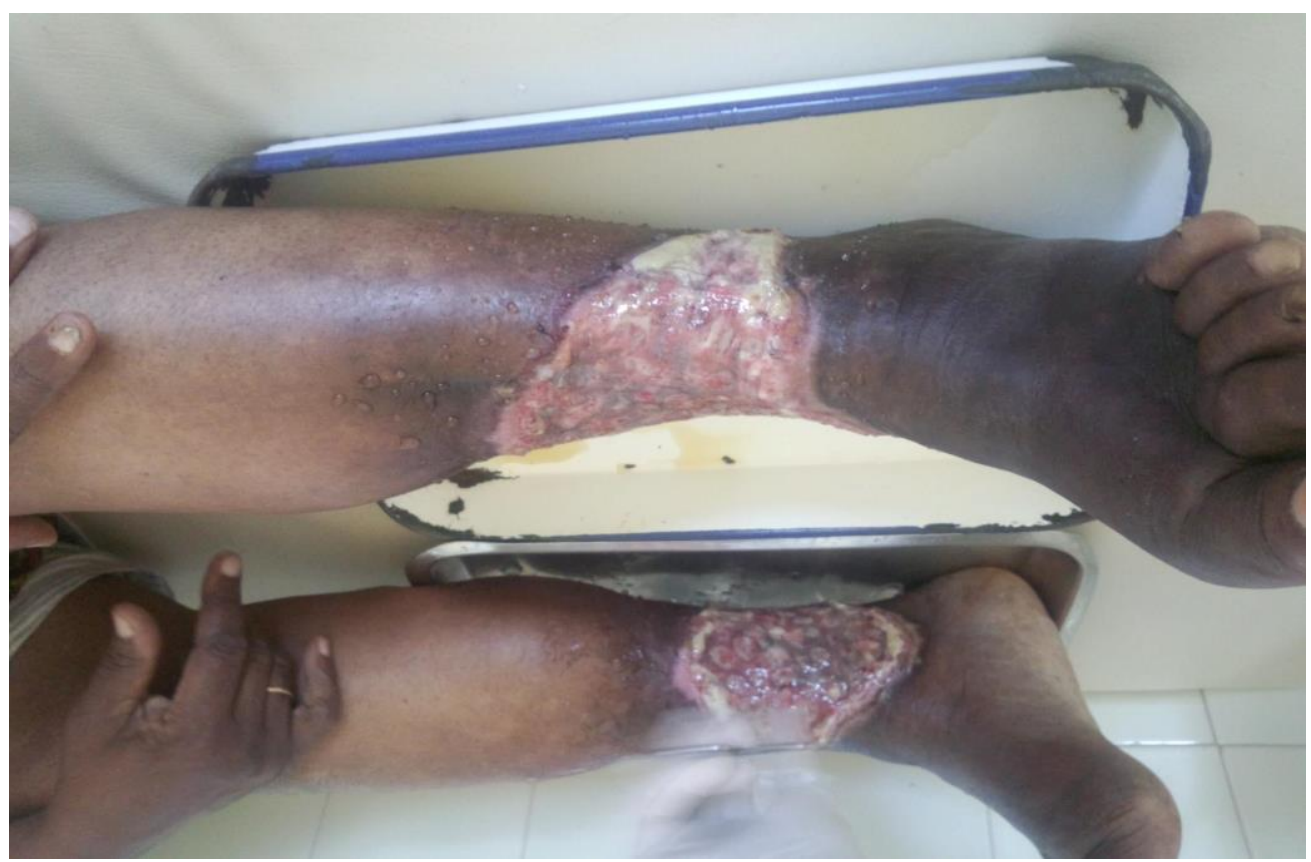

Figure 1: Bilateral venous ulcer in patient treated in JRA Hospital

DVT were proximal in 50 patients (47.16\%), located in iliofemoral vein in 20 patients $(18.86 \%)$ and in popliteal vein in 30 patients $(28.30 \%)$ (Table III). DVT were located in left side in 65 patients $(61.32 \%)$, in the right side in 39 patients (36.79\%) and bilateral in 2 patients (1.88\%). Duplex ultrasound showed venous abnormalities in 90 cases (84.90\%).

Table III : Duplex ultrasound results

\begin{tabular}{|l|l|c|c|}
\hline \multirow{2}{*}{ Duplex ultrasound resulst } & \multicolumn{2}{|c|}{$\begin{array}{c}\text { No. of Patients } \\
\text { (Total=106) }\end{array}$} & $\begin{array}{c}\text { Percentage } \\
\text { (\%) }\end{array}$ \\
\hline \multirow{4}{*}{ Location of initial DVT } & \multicolumn{1}{|c|}{ Ilio-femoral vein } & 20 & 18.86 \\
\cline { 2 - 4 } & Popliteal vein & 30 & 28.30 \\
\cline { 2 - 4 } & Tibial vein & 56 & 52.83 \\
\hline \multirow{5}{*}{ Side of the DVT } & Left & 65 & 36.32 \\
\cline { 2 - 4 } & Right & 39 & 01.88 \\
\cline { 2 - 4 } & Bilateral & 02 & 54.71 \\
\hline \multirow{5}{*}{ PTS venous abnormalities } & Distended veins & 58 & 50.00 \\
\cline { 2 - 4 } & Non-compressible & 53 & 50.00 \\
\cline { 2 - 4 } & Reflux & 45 & 42.45 \\
\cline { 2 - 4 } & Limited lumen stenosis & 16 & 15.09 \\
\cline { 2 - 4 } & Normal & 53 & 36.79 \\
\hline
\end{tabular}

Management was non-interventional treatment and surgical treatment: non interventional-treatment were lifestyle changes in 48 patients (obese or overweight) (45.28\%), compression stockings for all patients $(100 \%)$ and anticoagulant therapy for all patients (100\%) (Table IV).
Surgical treatment were stripping in 34 patients $(32.07 \%)$, phlebectomy in 5 patients $(04.71 \%)$, stripping in association with phlebectomy in 30 patients $(28.30 \%)$. Local treatment has been performed in 11 patients $(10.37 \%)$ who presented venous ulcers. 
Table IV : Treatment of post thrombotic syndrome

\begin{tabular}{|c|c|c|c|}
\hline \multicolumn{2}{|c|}{ Treatment } & \multirow{2}{*}{$\begin{array}{c}\begin{array}{c}\text { No. of Patients } \\
\text { (Total=106) }\end{array} \\
48\end{array}$} & \multirow{2}{*}{$\begin{array}{c}\begin{array}{c}\text { Percentage } \\
\text { (\%) }\end{array} \\
45.28\end{array}$} \\
\hline \multirow{7}{*}{$\begin{array}{l}\text { Non-interventional } \\
\text { treatment }\end{array}$} & Lifestyle changes & & \\
\hline & Compression stockings & 106 & 100 \\
\hline & \multirow{5}{*}{$\begin{array}{l}\text { Anticoagulant therapy } \\
\text { - } \quad \text { < } 3 \text { months } \\
\text { - } 6 \text { months } \\
\text { - } \quad \text { 6-12 months } \\
\text { - } \quad>12 \text { months }\end{array}$} & 106 & 100 \\
\hline & & 106 & 54.71 \\
\hline & & 80 & 75.47 \\
\hline & & 51 & 48.11 \\
\hline & & 26 & 15.09 \\
\hline \multirow{4}{*}{$\begin{array}{l}\text { Surgical treatment } \\
\qquad(n=69)\end{array}$} & Stripping & 34 & 32.07 \\
\hline & Phlebectomy & 05 & 04.71 \\
\hline & Stripping + phlebectomy & 30 & 28.30 \\
\hline & Local treatment of ulcer & 11 & 10.37 \\
\hline
\end{tabular}

\section{DISCUSSION}

PTS is the most complications of DVT in patients with lower extremity deep venous thrombosis, including all symptoms and clinical signs after an episode of acute DVT. The pathophysiology of post thrombotic syndrome is unclear. However, some authors elucidated the pathophysiology of PTS, determining the role of chronic venous obstruction, venous insufficiency, increased exposure to inflammatory mediators and reduced mobility in patients who have DVT.5, 6

The frequency of PTS after a first episode of acute symptomatic DVT of lower extremity were variable according the study: $13 \%$ in Nishimoto's study, $11 \%$ in Ondze-Kafata's study and 12\% in Saleh's study.7,8,9 In our study, the frequency of PTS was higher than in these results $(33.65 \%)$. However, the frequency of PTS in our study was less than in Huang's study (47.7\%). ${ }^{10}$

Older age (greater than or equal to 60 years) is one of factors increased the risk of PTS after DVT.11 In our study, 8.49\% of patients was older than 60 years. The predominance of older age of patients are seen in several study but the average age varied according the study : 47 years in the one of Kahn's study, 50 years in Delluc's study, 63 years in Mant's study and 46 years in our study. ${ }^{12,13,14}$

Women were a significantly greater risk for PTS showed by some researchers.15,16 The predominance of female is still observed in several study of PTS as in Tick's study (53\%), in Huang's study (53\%) and in our study (71\%). ${ }^{15,10}$ This predominance of female could be explained by the presence of a significant risk of DVT in female than male $(p=0.003) .{ }^{17}$

In the literature, the relative importance of risk factors of PTS has been subject to considerable debate. According Kahn's study, the principal risk factors for PTS are anatomically extensive DVT, recurrent ipsilateral DVT, persistent leg symptoms 1 month after acute DVT, obesity, and older age. ${ }^{11}$ According to Tick's study, women, obese patients, patients with proximal DVT and those with varicose veins have an increased risk of PTS. ${ }^{15}$ However, other recent study showed the significant risk factors of PTS as in Nishimoto's study, in Huang's study and in Zhang's study.7,10,18 In our study, the most risk factors of PTS were obesity $(33.73 \%)$, previous history of varicose veins $(50 \%)$, sedentary lifestyle (45.28\%), insufficiency anticoagulation therapy (68.86\%) and proximal DVT (47.16\%).

PTS develops in $\sim 20 \%$ to $50 \%$ of patients within 2 years of DVT diagnosis. ${ }^{19}$ In our study, $81 \%$ of patients presented PTS greater than or equal to 2 years after an acute episode of DVT. The diagnosis of PTS is most difficult established. In Schulman's study, any sign of PTS was seen in $56.3 \%$ of the evaluated patients.20 According to the consensus of International Society on Thrombosis and Haemostasis (ISTH) in 2008, Villalta's score constitute the gold standard to etablish the diagnosis of PTS. Villalta's score is based on 5 symptom (pain, cramps, heaviness, paresthesia, pruritus) and six clinical signs (pretibial edema, skin indurations, hyperpigmentation, redness, venous ectasia, pain on calf compression). ${ }^{21}$ Points are given for each of these 11 descriptors according to severity, ranging from 0 for not present to 3 for severe. The patient was diagnosed as having PTS if the Villalta score was $\geq 5$ or if a venous ulcer was present. A score of 5-9 signifies mild disease, 10-14 moderate disease and $\geq 15$ or development of venous ulcer signifies severe disease. In our study, PTS was mild in 48 patients $(45.28 \%)$, moderate in 47 patients $(44.33 \%)$ and severe in 11 patients $(10.37 \%)$.

In the literature, mild forms is usually frequent than severe forms. According to Kahn's study, PTS were mild in 30\%, moderate in $10 \%$ and severe in $3 \%$ of patients. ${ }^{16}$ According the retrospective study of PTS in 11 children by Sharathkumar et al, PTS were moderate in $72 \%$ of patients and severe in $28 \%$ of patients. ${ }^{22}$ In Bigguzzi's study, PTS were mild in $55 \%$, moderate in $4 \%$ and severe in $4 \%$ of patients. ${ }^{23}$ Our study agrees with most studies in the literature in the predominance of mild form than severe form. According Schulman's study, the probability to develop severe PTS was $6 \% .^{20}$

Duplex ultrasound can provide additional information on location of initial DVT, extension of thrombosis. The advantage of duplex US is that the exam is inexpensive and non-invasive. In our study, DVT were located in proximal veins in $47.16 \%$ of patients which $18.86 \%$ in iliofemoral veins and $28.30 \%$ in popliteal veins. According to Bittar's study, DVT were located in proximal vein in $90.3 \%$ of cases and in distal vein in $9.7 \%$ of cases. ${ }^{24}$ In Huang's study, DVT 
were proximal in $82.2 \% .^{10}$ According to the literature, proximal DVT is a significant risk factor of PTS.15,25 The predominance of left side of DVT were observed in most studies as in Rabinovich's study, in Huang's study.26,10 According to Rabinovich study, DVT were located in left side in $55.4 \%$ of patients and in right side in $44.6 \% .{ }^{26}$ According to Huang study, DVT were located in left side in $65.4 \%$ and in right side in $34.6 \% .{ }^{10}$ Our results were similar to these study in the predominance of left side (61.32\%). This predominance of left side in DVT's location was due to the left-sided iliac vein compression syndrome, also known as May-Thurner syndrome, which explains the starting point of DVT from this location. ${ }^{27,28}$ However, Avila's study in children PTS showed the predominance of right side (50\%) than left side (43\%). ${ }^{29}$ Duplex ultrasound could analyzed the anatomy and hemodynamic profile of lower-limb veins. For post thrombotic syndrome, duplex ultrasound can recognize specific anatomical abnormalities in the venous lumen, wall, and valves. ${ }^{30}$ In our study, venous abnormalities were encountered in $84.90 \%$ of results of duplex utrasound.

If the duplex US is inconclusive or additional anatomical information is required, CT or MR venography can be performed to evaluate for venous collaterals, masses that may cause extrinsic compression of veins, and venous asymmetries.

Currently debate continues about the best strategies for the management of PTS. There is no consensus about management of PTS. However, Kahn and al has etablished guidance for the prevention and treatment of PTS in 2016.31 Otherwise, some researchers has elucidated in recent studies the prevention and management of PTS as in Makedonov's study in 2020, in Rabinovich's study in 2018, in Ten CateHoek's study in 2018 and in Azirar's study. $32,33,34,35$ Now, there are some therapeutic possibilities to treat PTS after an episode of DVT: lifestyle change, compression stockings, pharmacotherapy and surgical treatment. ${ }^{36}$ These therapeutic possibilities could be used isolated or in combination. In our study, the therapeutic modalities were $45 \%$ lifestyle changes, $100 \%$ compression stockings, $69 \%$ pharmacotherapy and $65 \%$ surgical treatment. The efficacy of compression stockings to prevent PTS in patients with DVT has been demonstrated in Burgstaller's study. ${ }^{37}$ The results of two randomized controlled trials (RCTs) in Burgstaller's study showed a statistically significant reduction in PTS of $50 \%$ or more after two or more years of using active compression stockings. ${ }^{37}$ Anticoagulation insufficiency is one of risk factors for developing PTS. So, the use of anticoagulant medication such as direct oral anticoagulants (DOACs) might decrease PTS incidence in patients presenting DVT.34 Recurrent ipsilateral DVT is an important risk factor for PTS so preventing recurrent DVT by providing optimal, appropriate-duration anticoagulation for the initial DVT is an important goal of management. In our study, all patients received an anticoagulation treatment by vitamin $\mathrm{K}$ antagonist but $48.11 \%$ of patients received anticoagulant therapy during greater than or equal to 6 months. It could be explained by the cost of treatment which many patients could not follow for a long time. However, Shulman and al. analogously showed in a 10 year follow-up study of the Duration of Anticoagulation (DURAC) trial that the risk of PTS was not significantly different between the 6 weeks and 6 months arms. ${ }^{38}$

Surgery or endovascular therapy should be considered as complementary to medical management. Early surgical or endovascular intervention in appropriately selected patients may decrease the incidence of recurrent ulceration and skin changes and provide a better quality of life. Khanna and al have described the surgical possibilities to treat PTS in 2012.39 Venous obstruction requires endovenous stenting, endophlebectomy, or open bypass procedures. Venous stripping, foam sclerotherapy, radiofrequency, or laser ablation are used to abolish superficial venous reflux. Valvuloplasty procedures are useful for incompetent valve but in intact deep venous valves, while transposition vein or axillary vein autotransplantation is done for completely destroyed valves. In our study, surgical treatment was stripping (32.07\%), phlebectomy (4.71\%) and stripping in association with phlebectomy in 30 patients $(28.30 \%)$. The treatment of chronic venous ulcers is a therapeutic challenge. Rai concluded that patients with nonhealing venous ulcers who have had compression therapy and have no deep vein incompetence are recommended for superficial venous surgery, foam sclerotherapy or ligation of the affected vein as an important aspect of the overall treatment plan. ${ }^{40}$ Prevention of recurrences includes regular clinical evaluations, patient education about skin care, elevation, exercise and life-long compression therapy. In our practice, the treatment of venous ulcer includes local treatment (debridement, dressings, and skin graft), compression stockings and stripping.

\section{CONCLUSION}

PTS increases healthcare costs and reduces quality of life of patients. The frequency of PTS after an acute episode of DVT was $33.65 \%$ in our study. DVT required an early management to prevent PTS. Venous ulcer is the most serious clinical signs which treatment requires control of the high pressure in the leg veins and treating the ulcer.

\section{Acknowledgements:}

None.

\section{Conflicts of Interest:}

The authors have no conflicts of interest to declare.

\section{REFERENCES}

1. Maleti 0 , Lugli M, Perrin M. Syndrome post-thrombotique. EMC-Cardiologie 2013;8: 1-12. [Article 11-740-A-10]

2. Galanaud, JP, Monreal M, Kahn SR. Epidemiology of the postthrombotic syndrome. Thrombosis research 2018; 164:100109.

3. Ashrani AA, Heit JA. Incidence and cost burden of postthrombotic syndrome. Journal of thrombosis and thrombolysis 2009; 28(4):465-476.

4. Ma H, O'Donnell Jr TF, Rosen NA, Iafrati MD. The real cost of treating venous ulcers in a contemporary vascular practice. Journal of Vascular Surgery: Venous and Lymphatic Disorders 2014; 2(4):355-361.

5. Bergan JJ, Schmid-Schönbein GW, Smith PDC, Nicolaides AN, Boisseau MR, Eklof B. Chronic venous disease. New England Journal of Medicine 2006; 355(5):488-498.

6. Kayssi A, Roche-Nagle G. Postthrombotic syndrome. CMAJ 2014; 186(1):62-62.

7. Nishimoto $Y$, Yamashita $Y$, Morimoto $T$, Saga S, Amano $H$, Takase $\mathrm{T}$ et al. Risk factors for post-thrombotic syndrome in patients with deep vein thrombosis: from the COMMAND VTE registry. Heart and vessels 2019; 34(4):669-677.

8. Ondze-Kafata LI, Kouala Landa C, Traore-Kissima A, Loumouamou M, Bani M, Amounya-Zobo S. La thrombose veineuse des membres inférieurs à brazzaville: à propos de 44 cas. Cardiologie Tropicale 2012; 135:1-11.

9. Saleh MI, Atalla KA, Taha AG, Sayed AK. Short-term patency of catheter-directed thrombolysis for iliofemoral deep vein thrombosis. The Egyptian Journal of Surgery 2018; 37(3):309315.

10. Huang H, Gu JP, Shi HF, Shi WY, Lu JY, Chen L et al. Assessment of the probability of post-thrombotic syndrome in patients 
with lower extremity deep venous thrombosis. Scientific reports 2018; 8(1):1-7.

11. Kahn SR. The post-thrombotic syndrome. Hematology Am Soc Hematol Educ Program. 2016; 2016(1):413-418.

12. Kahn SR, Shrier I, Shapiro S, Houweling AH, Hirsch AM, Reid $\mathrm{RD}$ et al. Six-month exercise training program to treat postthrombotic syndrome: a randomized controlled two-centre trial. Cmaj 2011; 183(1):37-44.

13. Delluc A, Gouedard C, De LSM, Garcia C, Roguedas AM, Bressollette $\mathrm{L}$ et al. Incidence, facteurs de risque et signes cutanés de la maladie post-thrombotique : suivi à quatre ans des patients inclus dans l'étude EDITH. La Revue de médecine interne 2010; 31(11):729-734.

14. Mant MJ, Eurich DT, Russell DB, Majumdar SR. Postthrombotic syndrome after total hip arthroplasty is uncommon. Acta orthopaedica 2008; 79(6):794-799.

15. Tick LW, Kramer MH, Rosendaal FR, Faber WR, Doggen CJM. Risk factors for post-thrombotic syndrome in patients with a first deep venous thrombosis. Journal of Thrombosis and Haemostasis 2008; 6(12):2075-2081.

16. Kahn SR, Shrier I, Julian JA, Ducruet T, Arsenault L, Miron MJ et al. Determinants and time course of the postthrombotic syndrome after acute deep venous thrombosis. Annals of internal medicine 2008;149(10):698-707.

17. Alshoabi SA, Mothanna A. Deep Venous Thrombosis: Commonly Affected Veins in the Lower Limbs. Journal of Biosciences and Medicines 2019; 7(3):12-19.

18. Zhang Z, Song K, Yao Y, Jiang T, Pan P, Jiang Q. Incidence and risk factors for post-thrombotic syndrome in patients with deep vein thrombosis following total knee and hip arthroplasty. The Journal of arthroplasty 2019; 34(3):560563.

19. Kahn SR, Comerota AJ, Cushman M, et al; American Heart Association Council on Peripheral Vascular Disease, Council on Clinical Cardiology, and Council on Cardiovascular and Stroke Nursing. The postthrombotic syndrome: evidence-based prevention, diagnosis, and treatment strategies: a scientific statement from the American Heart Association. Circulation. 2014; 130(18):1636-1661

20. Schulman S, Lindmarker P, Holmstro"mM, Lärfars G, Carlsson $A$, Nicol $\mathrm{P}$ et al. Post-thrombotic syndrome, recurrence, and death 10 years after the first episode of venous thromboembolism treated with warfarin for 6 weeks or 6 months. J Thromb Haemost 2006; 4:734-42.

21. Soosainathan A, Moore HM, Gohel MS, Davies AH. Scoring systems for the post-thrombotic syndrome. Journal of vascular surgery 2013; 57(1):254-261.

22. Sharathkumar AA, Pipe SW. Post-thrombotic syndrome in children: a single center experience. Journal of Pediatric Hematology/Oncology 2008; 30(4):261-266.

23. Biguzzi E, Mozzi E, Alatri A, Taioli E, Moia M, Mannucci PM. The post-thrombotic syndrome in young women: retrospective evaluation of prognostic factors. Thromb Haemost. 1998; 80(4):575-577.

24. Bittar LF, Silva LQD, Orsi FLDA, Zapponi KCS, Mazetto BDM, Paula EVD. Increased inflammation and endothelial markers in patients with late severe post-thrombotic syndrome. Plos one 2020; 15(1):e0227150.
25. Stain M, Schönauer V, Minar E, Bialonczyk C, Hirschl M, Weltermann A, Kyrle PA, Eichinger S. The post-thrombotic syndrome: risk factors and impact on the course of thrombotic disease. J Thromb Haemost 2005; 3:2671-6.

26. Rabinovich A, Ducruet $\mathrm{T}$, Kahn SR, SOX Trial Investigators, Shapiro S, Tagalakis V et al. Development of a clinical prediction model for the postthrombotic syndrome in a prospective cohort of patients with proximal deep vein thrombosis. Journal of Thrombosis and Haemostasis 2018; 16(2):262-270.

27. Baekgaard N. Incidence and location of deep vein thrombosis in the lower extremities: what do we know. Phlebolymphology 2017; 24(2):97-104.

28. Brinegar KN, Sheth RA, Khademhosseini A, Bautista J, Oklu R. Iliac vein compression syndrome: clinical, imaging and pathologic findings. World journal of radiology 2015; 7(11):375-381.

29. Avila ML, Pullenayegum E, Williams S, Yue N, Krol P, Brandão LR. Postthrombotic syndrome and other outcomes of lower extremity deep vein thrombosis in children. Blood 2016; 128(14):1862-1869.

30. Pichot $\mathrm{O}$, Menez $\mathrm{C}$. Role of duplex ultrasound investigation in the management of postthrombotic syndrome. Phlebolymphology 2016; 23(2):102-111.

31. Kahn SR, Galanaud JP, Vedantham S, Ginsberg JS. Guidance for the prevention and treatment of the post-thrombotic syndrome. Journal of thrombosis and thrombolysis, 2016; 41(1):144-153.

32. Makedonov I, Kahn SR, Galanaud, JP. Prevention and Management of the Post-Thrombotic Syndrome. J Clin Med 2020; 9(4), 923.

33. Rabinovich A, Kahn SR. How I treat the postthrombotic syndrome. Blood 2018; 131(20):2215-2222.

34. Ten Cate Hoek AJ. Prevention and treatment of the post thrombotic syndrome. Research and practice in thrombosis and haemostasis 2018; 2(2), 209-219.

35. Azirar S, Appelen D, Prins MH, Neumann MH, de Feiter AN Kolbach DN. Compression therapy for treating post-thrombotic syndrome. Cochrane Database of Systematic Reviews 2019; (9).

36. Yamaki T. Post-thrombotic syndrome-Recent aspects of prevention, diagnosis and clinical management. Reviews in Vascular Medicine 2016; 6:10-19.

37. Burgstaller JM, Steurer J, Held U, Amann-Vesti B. Efficacy of compression stockings in preventing post-thrombotic syndrome in patients with deep venous thrombosis: a systematic review and metaanalysis. Vasa. 2016; 45(2):141-7.

38. Schulman S, Lindmarker P, Holmstrom M, Larfars G, Carlsson A, Nicol P et al. Post-thrombotic syndrome, recurrence, and death 10 years after the first episode of venous thromboembolism treated with warfarin for 6 weeks or 6 months. J Thromb Haemost 2006; 4:734-742.

39. Khanna AK, Singh S. Postthrombotic syndrome: surgical possibilities. Thrombosis 2012; 2012.

40. Rai R. Standard guidelines for management of venous leg ulcer. Indian Dermatol Online J 2014; 5(3):408-41. 